Original article

\title{
Knowledge, attitude, and practice on insulin administration among diabetic patients and their caregivers - Cross-sectional study
}

\author{
Anu Sunny ${ }^{\text {a }}$, Uday Venkat Mateti ${ }^{\text {a, }}$, Adithi Kellarai ${ }^{\mathrm{b}}$, Shraddha Shetty ${ }^{\mathrm{c}}$, \\ Shaikh Rafiya Rafikahmed ${ }^{a}$, Shivaprasad Sirimalla ${ }^{a}$, Anjana Madhusoodanan ${ }^{a}$ \\ ${ }^{a}$ Nitte (Deemed to be University), NGSM Institute of Pharmaceutical Sciences, Department of Pharmacy Practice, Deralakatte, Mangaluru, Karnataka, India \\ ${ }^{\mathrm{b}}$ Nitte (Deemed to be University), KS Hegde Medical Academy, Justice KS Hegde Charitable Hospital, Department of General Medicine, Deralakatte, Mangaluru, \\ Karnataka, India \\ ${ }^{\mathrm{c}}$ Nitte (Deemed to be University), KS Hegde Medical Academy, Department of Biostatistics, Deralakatte, Mangaluru, Karnataka, India
}

\section{A R T I C L E I N F O}

\section{Keywords:}

Diabetes

Insulin

Knowledge

Attitude

Practice

\begin{abstract}
A B S T R A C T
Introduction: Insulin therapy is the cornerstone treatment of diabetic patients. Most diabetic patients cannot selfadministrate insulin due to various reasons to depend on caregivers.

Objectives: To assess the knowledge, attitude, and practice (KAP) on insulin administration among diabetic patients and their caregivers.

Methods: A prospective cross-sectional study was conducted for seven months. All diabetic patients age above 18 years who were on insulin therapy for more than six months were included in the study. Patient medical records were used to collect demographic information such as age, gender, educational status, occupation, socioeconomic class, HbA1c, and insulin duration. The validated KAP questionnaire was used for the assessment of KAP among patients or caregivers.

Results: A total of 255 patients were included, out of which $163(63.92 \%)$ were male and $92(36.07 \%)$ were female. The mean KAP score was $65.05 \pm 14$. There is no significant correlation between the HbA1c levels with KAP scores among diabetic patients. There is a significant link between the knowledge, attitude, and Overall KAP patients with education qualification ( $\mathrm{p}<0.05)$, occupation $(\mathrm{p}<0.05)$, economic class of the patients $(\mathrm{p}<0.05)$, and duration of insulin treatment $(\mathrm{p}<0.05)$.

Conclusion: The patients average age was 55.74 years. The results showed that the mean KAP score was 65.05 , which is less and most of the patients had not controlled their glycemic levels. Effective education regarding insulin administration and glycemic control improves the KAP among patients or caregivers.
\end{abstract}

\section{Introduction}

According to the International Diabetes Federation (IDF), more than $80 \%$ of diabetes patients reside in low- and middle-income nations. ${ }^{1}$ Diabetes is estimated to affect 463 million people in 2019, with this figure expected to rise to 578 million by 2030 and 700 million by $2045 .^{2}$ Type 2 diabetes mellitus (DM) is most common after middle age, affecting both sexes equally and most commonly occurring between the ages of 50 and 70 . Type $1 \mathrm{DM}$ is most commonly occurs at 10-12 years with slight male supremacy. However, in some cases, elderly people can have Type $1 \mathrm{DM}$, and children can have type $2 \mathrm{DM} .{ }^{3}$ Insulin is a powerful and necessary drug for controlling blood sugar levels. The chief advocated for treatment in patients with Type 1 diabetes, and it is frequently used as an adjuvant to oral hypoglycemic agents in patients with Type 2 diabetes who have not met their target blood glucose level. The main goal of diabetes management is to keep blood sugar levels within normal ranges. In order to meet this criterion. ${ }^{4}$ Insulin is available in its speed of action like rapid, short, intermediate, and long-acting types. Insulin administration is performed on different body sites, in which the abdomen is the most common site for injection.

Self-administration of insulin depends on the knowledge and attitude of the patient on insulin therapy. Various studies have been carried out worldwide regarding the knowledge attitude and practice (KAP) of patients on self-administration of insulin. The studies reported that the KAP might vary depending on age, gender, marital status, educational background, employment, urban residence, duration of disease, etc. ${ }^{6,7,8}$

\footnotetext{
* Corresponding author.

E-mail address: udayvenkatmateti@gmail.com (U.V. Mateti).
} 
Knowledge about the administration of insulin is essential in diabetic patients. Various Indian studies have been emphasized diabetic epidemiology, but studies related KAP survey in diabetes are limited., 10,11 Previously conducted studies have not assessed the correlation between KAP scores and glycemic control. Most diabetic patients cannot self-administrate insulin for various reasons (elderly patients, multiple diseases, presence of psychological problems and cognitive impairment, the complexity of treatment, etc.), so they may depend on caregivers. Hence the present study aims to conduct the KAP on insulin administration among DM patients or their caregivers and assess the correlation between KAP scores and glycemic control.

\section{Methods}

\subsection{Study design, setting, and participants}

A prospective cross-sectional study design was conducted in the general medicine unit of a tertiary care teaching hospital. The current study is a 7-month hospital-based study. The sample size was calculated at the beginning of the study $(n=255)$ was arrived at by considering previous records of patients on insulin therapy visiting the hospital in the preceding years.

\subsection{Ethical permission and registry}

Before starting the KAP survey, permission was obtained from the Institutional Ethics Committee of NGSM Institute of Pharmaceutical Sciences, Mangaluru (Ref. No: NGSMIPS/IEC/04/2020) and the study registered under the Clinical Trials Registry of India (Ref. No: CTRI/ 2020/12/029782).

\subsection{Study criteria}

All the diabetic patients of age above 18 years and either gender on insulin therapy for more than six months and patients willing to answer KAP questions (self-administration or administration by caregivers) were included. Patients who cannot give informed consent, patients with mental illness, pregnant women, and critically ill patients were not included in the study.

\subsection{Development of knowledge, attitude and practices (KAP) questionnaire}

The KAP questionnaire was developed by referring to primary, secondary and tertiary resources. Primary resources include various articles $^{9,12,13}$ related to administration of insulin. Secondary resources include databases such as UpToDate, Medscape and WebMD. ${ }^{14,15,16}$ Tertiary resources include the pharmacotherapy textbook. ${ }^{17}$ The KAP questionnaire consists of 15 questions based on knowledge $(n=5)$, attitude $(n=5)$ and practice $(n=5)$ of insulin administration (The KAP questionnaire is attached as Supplementary data).

\subsection{Validation and translation of KAP questionnaire}

The KAP questionnaire was validated by an expert committee of doctors $(n=3)$, academic pharmacist $(n=2)$, nurse $(n=1)$. Necessary changes were made in the questionnaire as per the expert guidance. The validated KAP questionnaire was translated into Kannada and Malayalam using a three-step method that included forward translation, reverse translation, and patient testing.

\subsection{Reliability of KAP questionnaire}

Two interviews were done seven days apart in the same patients to test the reliability of the KAP questionnaire. The cronbach's alpha value $\geq 0.70$ was considered as reliable. The reliability test was conducted on
40 patients, 20 of whom spoke Kannada, and 20 spoke Malayalam.

\subsection{Data collection}

Patients who met the inclusion criteria were assessed for the KAP of insulin administration. The details such as age, gender, educational status, occupation, HbA1c, duration of insulin treatment, socioeconomic class ${ }^{18}$ were collected from patient medical records. Glycemic control was assessed based on HbA1c levels. It was considered as controlled blood sugar, if the HbA1c level is $<7 \%$, and not controlled, if the HbA1c level $>7 \%{ }^{19}$

\subsection{Assessment of outcome}

The KAP was evaluated using the following formula:

KAP Score Evaluation $=\frac{\text { Total number of correct respones answered }}{\text { Total number of actual correct responses }}=100$

\subsection{Statistical analysis}

The difference in KAP of self-administered patients and caregivers, glycemic control and KAP score; gender, and domiciliary status was assessed by an independent sample $t$-test. The difference in KAP scores and education qualification, occupation, economic class of the patients, and duration of insulin treatment was assessed by the ANOVA test. Pearson Correlation evaluated the correlation between the HbA1C levels with KAP score. The p-value $<0.05$ was conceded as statistically significant. The statistical analysis were performed using SPSS software version 20.0 .

\section{Results}

\subsection{Demographic characteristics}

In this study, a total of 255 patient data was collected. Out of 255, $64.70 \%$ of patients $(n=165)$ self-administered their insulin injection and $35.29 \%$ of them by caregivers $(n=90)$. The average age of the overall patients was $55.74 \pm 12.97$ years. The most of the patients (63.92\%) were men, followed by women $(36.07 \%)$, and $38.03 \%$ had completed middle school. Of the total population considered $57.25 \%$ were unemployed, $82.35 \%$ were living in the rural area, and $64.70 \%$ of patients came under the socioeconomic class of upper-lower as described in Table 1 . The median duration of diabetes for overall patients was 6 (11-3) years, and the median duration of insulin treatment for overall patients was 1 (3-0.70) years.

\subsection{Reliability of KAP questionnaire}

The reliability test was on 40 patients, among which 20 were Kannada and 20 were Malayalam patients, and the results found that the KAP questionnaire is reliable with the cronbach's alpha value $>0.70$. The details are described in Table 2.

\subsection{Assessment of KAP among self-administered patients and caregivers}

The mean KAP scores among self-administered patients and caregivers were $65.05 \pm$ and $64.52 \pm$, respectively $(\mathrm{p}=0.571)$. There is no measurable difference in KAP scores between diabetic patients and their care givers. The detailed KAP scores are presented in Table 3.

\subsection{Assessment of glycemic control among DM patients}

Out of 255 patients, $7.45 \%$ of patients $(n=19)$ had glycemic control with mean HbA1C levels of $6.25 \% \pm 0.47 \%$ and $92.54 \%$ patients $(n=236)$ had not controlled glycemic levels with a mean HbA1C levels of 
Table 1

Demographic details of patients.

\begin{tabular}{|c|c|}
\hline Demographic characteristics & Frequency $(\mathrm{n}=255)(\%)$ \\
\hline \multicolumn{2}{|l|}{ Age groups } \\
\hline $18-30$ & $11(4.31 \%)$ \\
\hline $31-45$ & $40(15.68 \%)$ \\
\hline $45-60$ & $110(43.13 \%)$ \\
\hline More than 60 & $94(36.86 \%)$ \\
\hline \multicolumn{2}{|l|}{ Gender } \\
\hline Male & $163(63.92 \%)$ \\
\hline Female & $92(36.07 \%)$ \\
\hline \multicolumn{2}{|l|}{ Education qualification } \\
\hline Illiterate & $13(5.09 \%)$ \\
\hline Primary school & $93(36.47 \%)$ \\
\hline Middle school & $97(38.03 \%)$ \\
\hline High school & $17(6.66 \%)$ \\
\hline Post high school & $5(1.96 \%)$ \\
\hline Graduate or postgraduate & $24(9.41 \%)$ \\
\hline Professional degree & $6(2.35 \%)$ \\
\hline \multicolumn{2}{|l|}{ Occupation } \\
\hline Unemployed & $146(57.25 \%)$ \\
\hline Unskilled worker & $35(13.72 \%)$ \\
\hline Semiskilled worker & $2(0.78 \%)$ \\
\hline Skilled worker & $18(7.05 \%)$ \\
\hline Clerical, shop owner/farm & $39(15.29 \%)$ \\
\hline Semi professional & $2(0.78 \%)$ \\
\hline Professional & $13(5.09 \%)$ \\
\hline \multicolumn{2}{|l|}{ Socio-economic class } \\
\hline Upper & $1(0.39 \%)$ \\
\hline Upper middle & $25(9.80 \%)$ \\
\hline Lower middle & $27(10.58 \%)$ \\
\hline Upper lower & $165(64.70 \%)$ \\
\hline Lower & $37(14.50 \%)$ \\
\hline \multicolumn{2}{|l|}{ Domiciliary status } \\
\hline Rural & $210(82.35 \%)$ \\
\hline Urban & $45(17.64 \%)$ \\
\hline \multicolumn{2}{|l|}{ Duration of insulin (In years) } \\
\hline$<2$ & $156(61.17 \%)$ \\
\hline $2-5$ & $61(23.92 \%)$ \\
\hline $6-10$ & $28(10.98 \%)$ \\
\hline$>10$ & $10(3.92 \%)$ \\
\hline
\end{tabular}

Table 2

Reliability of Kannada and Malayalam language KAP questionnaire.

\begin{tabular}{llll}
\hline \multicolumn{4}{l}{ Reliability of Kannada language KAP questionnaire } \\
\hline Domains & $\begin{array}{l}\text { Day } 1 \text { Test Score } \\
\text { (Mean } \pm \text { SD) }\end{array}$ & $\begin{array}{l}\text { Day 7 Test Score } \\
(\text { Mean } \pm \text { SD) }\end{array}$ & $\begin{array}{l}\text { Cronbach's alpha } \\
\text { value }\end{array}$ \\
\hline Knowledge & $59 \pm 16.51$ & $61 \pm 16.51$ & 0.964 \\
Attitude & $72 \pm 19.89$ & $73 \pm 18.66$ & 0.986 \\
Practice & $68 \pm 16.41$ & $68 \pm 16.41$ & 1 \\
KAP & $66.33 \pm 11.74$ & $67.33 \pm 10.57$ & 0.988 \\
Reliability of & Malayalam language KAP questionnaire & \\
Knowledge & $57 \pm 13.41$ & $58 \pm 14.36$ & 0.973 \\
Attitude & $73 \pm 20.79$ & $74 \pm 2.62$ & 0.988 \\
Practice & $65 \pm 15.72$ & $66 \pm 17.29$ & 0.981 \\
KAP & $64.99 \pm 12.21$ & $65.99 \pm 12.95$ & 0.990 \\
\hline
\end{tabular}

$8.97 \%+1.74 \%$. Out of 19 glycemic control patients, 10 patients $(6.06 \%)$ were self-administered, and 9 patients $(10 \%)$ were caregivers administered patients. The detailed glycemic control among DM patients is presented in Table 3.

\subsection{Factors affecting KAP of diabetic patients}

There is a significant association between the Knowledge, Attitude, and Overall KAP patients with education qualification $(\mathrm{p}<0.05)$, occupation ( $p<0.05)$, economic class of the patients $(p<0.05)$, and duration of insulin treatment $(\mathrm{p}<0.05)$. The details are presented in Table 4.
Table 3

Assessment of KAP and glycemic control.

\begin{tabular}{|c|c|c|c|}
\hline Assessment & $\begin{array}{l}\text { Self-administered } \\
\text { Patients }(\mathrm{n}=165)\end{array}$ & Caregivers $(n=90)$ & $\begin{array}{l}\mathrm{p}- \\
\text { value }\end{array}$ \\
\hline $\begin{array}{l}\text { Knowledge } \\
\text { Score }\end{array}$ & $57.69 \pm 18.26$ & $60.66 \pm 17.59$ & 0.249 \\
\hline $\begin{array}{l}\text { Attitude } \\
\text { Score }\end{array}$ & $75.15 \pm 18.76$ & $72.22 \pm 20.70$ & 0.150 \\
\hline Practice Score & $62.78 \pm 16.51$ & $62.66 \pm 18.77$ & 0.50 \\
\hline KAP Score & $65.05 \pm 14.62$ & $64.52 \pm 15.77$ & 0.571 \\
\hline \multicolumn{4}{|c|}{ Assessment of glycemic control among diabetic patients } \\
\hline Assessment & $\begin{array}{l}\text { Glycemic Controlled } \\
\text { Patients }(n=19)\end{array}$ & $\begin{array}{l}\text { No Glycemic Controlled } \\
\text { Patients }(n=236)\end{array}$ & $\begin{array}{l}\text { p- } \\
\text { value }\end{array}$ \\
\hline $\begin{array}{l}\text { Knowledge } \\
\text { Score }\end{array}$ & $60 \pm 16.32$ & $58.64 \pm 18.21$ & 0.590 \\
\hline $\begin{array}{l}\text { Attitude } \\
\text { Score }\end{array}$ & $73.68 \pm 17.70$ & $74.15 \pm 19.64$ & 0.335 \\
\hline Practice Score & $61.05 \pm 20.51$ & $62.88 \pm 17.06$ & 0.610 \\
\hline KAP Score & $64.90 \pm 11.93$ & $64.85 \pm 15.24$ & 0.111 \\
\hline
\end{tabular}

\section{Discussion}

Insulin therapy necessitates the understanding and cooperation of both the patient and caregiver. Diabetes patient's condition can worsen due to improper insulin administration. Therefore, it is necessary to assess the patients or caregiver's KAP on insulin administration. In this study, the average age of the study population was $55.74 \pm 12.97$ years. The results were consistent with the similar studies conducted by Chawla SP et al., and Solanki JD et al., where the mean age was $55.50 \pm$ $9.37^{20}$ and $56.64 \pm 13.21$ years $^{13}$ respectively.

The study noticed that $163(63.92 \%)$ male patients outnumbered female patients $92(36.07 \%)$. Similar findings were found in the studies conducted by Shrestha D et al., and Dinesh PV et al., where the majority of the patients were male $58 \%,{ }^{12} 61.25 \%{ }^{\text {[21], }}$ respectively. In the present study, most patients (38.03\%) were having a middle school education. The study results were in contrast with similar studies conducted by Dinesh PV et al., where most patients have upper primary schooling. ${ }^{21}$ The study conducted by Netere AK et al., showed that most of the patients $(31.3 \%)$ had primary and secondary education. ${ }^{4}$ In the present study, the majority of the patients were unemployed. A study conducted by Berhe KK et al., showed that most patients (34.3\%) were unemployed. ${ }^{2}$ However, according to a study done by Dinesh PV et al., reported that most of the patients (28.5\%) were agriculturists and self-employed. ${ }^{21}$

The median duration of insulin treatment for overall patients was 1 (3-0.60) years. This result was in contrast with the study conducted by Netere AK et al., where the mean duration of insulin $2.3 \pm 0.8$ years. ${ }^{4}$ The present study found that most patients lived in rural areas $(82.35 \%)$, and the rest of the patients lived in urban areas $(17.64 \%)$. Similar findings were found in the studies conducted by Netere et al., and Mariye $\mathrm{T}$ et al., where most patients lived in rural areas $\left(51.8 \%{ }^{7}\right.$ and $59 \%,{ }^{22}$ respectively).

In the current study, the KAP questionnaire is reliable with Cronbach's alpha value $>0.7$ Similar findings were found in the studies conducted by Amiri P et al., and Werfalli MM et al., where the KAP questionnaire was reliable with cronbach's alpha value $>0.7^{23,24}$ The mean scores for knowledge, attitude, practice, and total KAP score were $57.69 \pm 18.26,75.15 \pm 18.76,62.78 \pm 16.51$, and $65.05 \pm 14.62$, respectively. Contradicted to the Surendranath et al., findings found that the mean scores for knowledge and practice were $46.9 \pm 3.98$ and 46.8 \pm 2.18 , respectively. ${ }^{3}$ Binhemd TA, conducted a study that showed that the mean KAP score was $84 \pm 11.6 .^{25}$

Our study shows a significant association between the KAP of patients with education qualification, occupation, economic class of patients, and duration of insulin treatment. This result was in contradiction to the study conducted by Solanki JD et al., where there was a significant association between age and educational level with KAP. ${ }^{13}$ In our study, 
Table 4

Education qualification and occupation vs. KAP assessment.

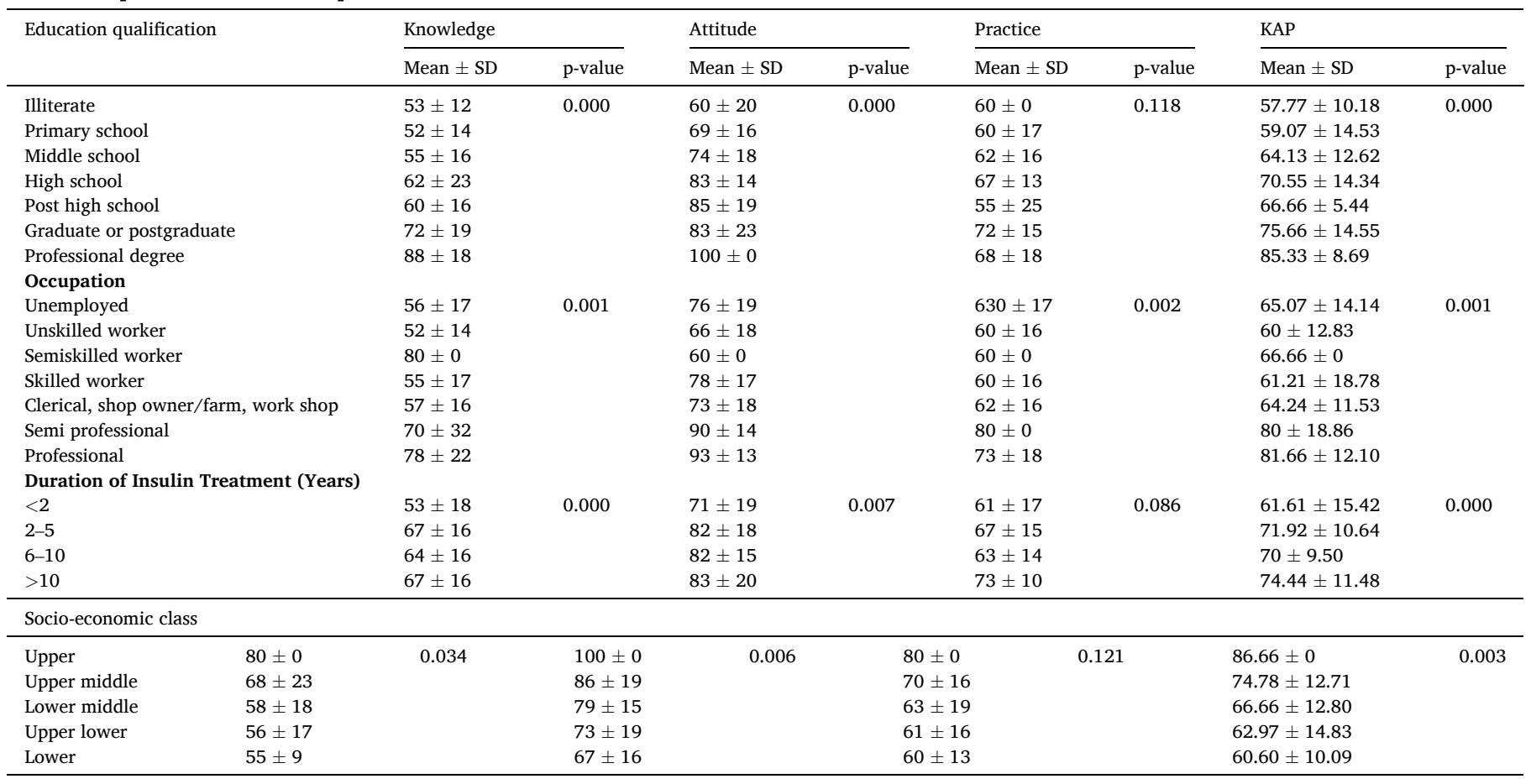

there is no significant correlation between the HbA1C levels with KAP scores. These results were in contrast with the study conducted by Solanki JD et al., where there was a positive correlation between the KAP score and glycemic control (HbA1C). ${ }^{13}$ The study conducted by Binhemd TA, reported a positive correlation between HbA1C and knowledge and a negative correlation with attitude and practice. ${ }^{25}$

\section{Limitations}

As the current study was conducted at a single center, the findings may not be extrapolated to the general population. The findings may not be generalized to a larger population since the study was conducted for seven months as it gives fewer data. Since it is a cross-sectional study, the findings cannot be generalized for a period of time.

\section{Conclusion}

In the present study, male patients surpassed the female patients. The mean age of the patients was 55.74 years. The results showed that the mean KAP score was 65.05 . There is a significant association between the knowledge, attitude, and overall KAP patients with education qualifications, occupation, economic class of the patients, and duration of insulin treatment. There is no significant correlation between the HbA1C levels with KAP score among diabetic patients, and most patients had not controlled their glycemic levels. Effective education regarding insulin administration and glycemic control improves the KAP among patients or caregivers.

\section{Funding}

There was no specific grant for this research from any funding agencies.

\section{Declaration of competing interest}

The authors state that they have no conflict of interest.

\section{Acknowledgement}

We would like to express our gratitude to the NGSM Institute of Pharmaceutical sciences, Nitte (Deemed to be University), Mangaluru for providing the research facilities for this study.

\section{Appendix A. Supplementary data}

Supplementary data to this article can be found online at https://doi. org/10.1016/j.cegh.2021.100860.

\section{References}

1 Patil M, Sahoo J, Kamalanathan S, et al. Assessment of insulin injection techniques among diabetes patients in a tertiary care centre. Diabet Metab Syndr. 2017;1(11): S53-S56.

2 Berhe KK, Gebru HB, Kahsay HB, Kahsay AA. Assessment of diabetes knowledge and its associated factors among type 2 diabetic patients in Mekelle and Ayder Referral Hospitals, Ethiopia. J Diabet Metabol. 2014;5(5), 1000378.

3 Surendranath A, Nagaraju B, Padmavathi GV, Anand SC, Fayaz P, Balachandra G. A study to assess the knowledge and practice of insulin self-administration among patients with diabetes mellitus. Asian J Pharmaceut Clin Res. 2012;5(1):63-66.

4 Netere AK, Ashete E, Gebreyohannes EA, Belachew SA. Evaluations of knowledge, skills and practices of insulin storage and injection handling techniques of diabetic patients in Ethiopian primary hospitals. BMC Publ Health. 2020;20(1), 1-0.

5 Shafi I, Parveen K, Hussain M, Afzal M, Gilani MA. Knowledge and practice on selfinsulin administration among diabetic patients in tertiary care hospital Lahore. Intensive Crit Care Nurs. 2020;3(3):1-7.

6 Peterson JM. Knowledge and attitude on insulin self-administration among type 1 diabetic patients at Metu Karl referral hospital, Ethiopia. J Diabet Res. 2019, 7801367.

7 Gholap MC, Mohite VR, Chendake MB. A study to assess the knowledge and practices of self administration of injection insulin among diabetic patient Attending out patient department of krishna hospital, karad. Int J Health Sci Res. 2016;6(9): 277-282.

8 Yilmaz UD, Tarhan S. Determination of attitude and knowledge of type 2 diabetic patients towards insulin therapy in Northern Cyprus. J Pakistan Med Assoc. 2017;67 (3):343-348, 8.

9 Shanmugam J, Roy A. Knowledge and awareness of insulin usage among diabetic patients in Chennai. Int J Sci Res. 2017;6(5):889-891.

10 Shah VN, Kamdar PK, Shah N. Assessing the knowledge, attitudes and practice of type 2 diabetes among patients of Saurashtra region, Gujarat. Int J Diabetes Dev Ctries. 2009;29(3):118-122. 
11 Malathy R, Narmadha M, Ramesh S, Alvin JM, Dinesh BN. Effect of a diabetes counseling programme on knowledge, attitude and practice among diabetic patients in Erode district of South India. J Young Pharm. 2011;3(1):65-72.

12 Shrestha D, Basnet S, Prajuli P, Baral D, Badhu A. Knowledge regarding selfadministration of insulin among the diabetic patients attending the diabetic clinic of tertiary care center of Easte rn Nepal. J Diabet Endo Assoc of Nepal. 2018;2(1):9-16.

13 Solanki JD, Sheth NS, Shah CJ, Mehta HB. Knowledge, attitude and practice of urban Gujarati type 2 diabetics: prevalence and impact on disease control. J Educ Health Promot. 2017;6(35):1-7.

14 Insulin therapy in type 2 diabetes mellitus. Available from: https://www.uptodate. $\mathrm{com} /$ contents/insulin-therapy-in-type-2-diabetesmellitus? search=INSULIN\&source $=$ search result\&selectedTitle $=3 \sim 142 \&$ usage $\_$type $=$default\&display_rank $=2$. Accessed December 10, 2020.

15 Taking insulin therapy to the next level: minimizing side effects \& maximizing glycemic control. Available from: https://www.medscape.org/viewarticle/937731. Accessed December 11, 2020.

16 Insulin for early type 2 diabetes. Available from: https://www.webmd.com/diabete s/news/20030821/insulin-for-early-type-2-diabetes. Accessed December 12, 2020.

17 Dipiro JT, Talber RL, Yee GC, Matzke GR, Wells BG, Posey LM. Diabetes mellitus. In: Triplit CL, Reasner CA, Isley WL, eds. Pharmacotherapy-A Pathophysiologic Approach. tenth ed. New York: McGraw Hill Education; 2017:1139-1179.

18 Wani RT. Socioeconomic status scales-modified Kuppuswamy and Udai Pareekh's scale updated for 2019. J Fam Med Prim Care. 2019;6(8):1846-1849.
19 American Diabetes Association. Glycemic targets: standards of medical care in diabetes-2021. Diabetes Care. 2021;44(Suppl 1):S73-S84.

20 Chawla SP, Kaur S, Bharti A, et al. Impact of health education on knowledge, attitude, practices and glycemic control in type 2 diabetes mellitus. J Fam Med Prim Care. 2019;8(1):261-268.

21 Dinesh PV, Kulkarni AG, Gangadhar NK. Knowledge and self-care practices regarding diabetes among patients with Type 2 diabetes in Rural Sullia, Karnataka: a Community-Based, Cross-Sectional Study. J Fam Med Prim Care. 2016;5(4):847-852.

22 Mariye T, Girmay A, Birhanu T, et al. Adherence to insulin therapy and associated factors among patients with diabetes mellitus in public hospitals of Central Zone of Tigray, Ethiopia, 2018: a cross-sectional study. Pan Afr Med J. 2019;33(309):1-10.

23 Niroomand M, Ghasemi SN, Karimi-Sari H, Kazempour-Ardebili S, Amiri P, Khosravi MH. Diabetes knowledge, attitude and practice (KAP) study among Iranian in-patients with type-2 diabetes: a cross-sectional study. Diabet Metab Syndr. 2016;10 (1):S114-S119.

24 Werfalli MM, Kalula SZ, Manning K, Levitt NS. Does social support effect knowledge and diabetes self-management practices in older persons with Type 2 diabetes attending primary care clinics in Cape Town, South Africa. PloS One. 2020;15(3), e0230173.

25 Binhemd TA. Diabetes mellitus: knowledge, attitude, practice and their relation to diabetes control in female diabetics. Ann Saudi Med. 1992;12(3):247-251. 